\title{
DO HENS SUFFER IN BATTERY CAGES? ENVIRONMENTAL PREFERENCES AND WELFARE
}

\author{
BY MARIAN DAWKINS \\ Animal Behaviour Research Group, Department of Zoology, Oxford
}

\begin{abstract}
The question 'Do hens suffer in battery cages?' is difficult to answer because of the problem of objectively assessing suffering in animals. It is argued that preference tests may be one way of throwing light on this difficult problem. This paper describes some experiments on habitat preference in domestic hens. No preference was observed between a commercial battery cage and a large pen when hens were given continuous access to the two. A simultaneous choice between a battery cage and an outside hen-run showed a clear preference for the run, but choice was strongly influenced by prior experience. The strength of the run preference was investigated by 'pitting' the run against food and access to companions.
\end{abstract}

\section{Introduction}

To many scientists the question 'Do hens suffer in battery cages?' is invalid, as it is a question about an animal's subjective feelings and the subjective feelings of animals are not directly accessible to scientific investigation. We may look for signs of physical ill-health and we can study behaviour, but we can never know for certain whether these observable symptoms are accompanied by subjective consciousness. We may study animals as if they were machines and try to discover what the behaviour machinery is by looking at the relation between inputs and outputs. There will be no place in such models for subjective feelings. But just because we study animals as if they were machines which merely behaved and felt nothing, does not mean that that is all they are. As Griffin (1976) points out: 'It is very easy for scientists to slip into the passive assumption that phenomena with which their customary methods cannot deal effectively are unimportant or even non-existent.' There are at least two reasons for believing that the subjective feelings of animals are both important and very far from non-existent.

The first reason comes from the way we react to other people. Exactly the same arguments apply to other human beings as to animals. Strictly, we can never know that other people have mental experiences. We cannot do an experiment to demonstrate that another human being is conscious or has feelings remotely like our own any more than we can for a hen or a chimpanzee. But commonsense and intuition tell us that other human beings probably do think and feel as we ourselves do. Their behaviour and physiology are sufficiently similar to our own that we are quite prepared to accept this without the need for logical proof. We base our ideas of morality, such as not to eat people, kill them or torture them, on this commonsense view rather than on strict logic. There is a 'common ground': suffering, pleasure, pain, which most people accept as being universals of human experience. But must this common ground stop at the boundaries of our own species? If we accept the evolutionary continuity between man and other animals for physiology, biochemistry and at least some aspects of behaviour, why not mental experiences too (Brophy 1972; Griffin 1976)? Ryder (1971) and Singer (1976) use the term 'speciesism' by analogy with racism. Many animals, particularly mammals and birds, seem to have all the basic nervous apparatus for feeling pain and experiencing emotion. Commonsense suggests that they can suffer. Of course, we cannot be certain about this, but neither can we about other people. If animals do suffer from some of our scientific experiments or from the ways in which we keep them for commercial profit, then it seems important on moral grounds to take this into account.

The second reason is a more biological one, and comes from consideration of the possible survival value of subjective feelings. We are accustomed to asking questions about the functional significance of the shape, colouring and behaviour of an animal. It is reasonable to assume that subjective feelings too evolved because animals which possessed them were fitter than those which did not. Exactly why they should have been fitter is one of the most profound mysteries of biology, and although various suggestions have been made, e.g. that they aided simulation of the future (Wall 1974), communication or learning, the full reasons are not 
understood. But whatever the reasons, each of us knows that we have subjective feelings and those feelings must be a product of natural selection. They are part of biology.

For these two reasons, questions about the mental states of animals are important: they are important on moral grounds in that if we ignore an animal's subjective feelings, we may be guilty of inflicting or at least condoning suffering in highly sentient and emotional beings; and they are important on biological grounds since subjective experience is part of an animal's equipment for survival.

This seems to bring us to an impasse: subjective feelings are important and yet we apparently cannot study them scientifically. There is, of course, no magic method for solving the major philosophical issues which still exist and gaining direct access into what animals are feeling. But I want to suggest that some behaviours are likely to be good indicators of mental state. The question is: which ones? I would like to discuss this question in relation to one particular problem which has recently aroused a lot of public concern-whether hens in battery cages suffer-but I hope that similar lines of reasoning can also be used for a wider range of problems.

Some of the most widely advocated indicators of possible suffering are physical ill-health, poor growth rate, or in the case of laying hens, a substandard number of eggs produced. Presumably physical health is an essential part of mental well-being, and it is often argued that productivity is in itself a sufficient guide on the grounds that animals which are suffering would not produce well. But, as pointed out by the Brambell Committee (Report, 1965), it is quite possible for animals to be growing or laying well, despite periods of acute but transitory physical or mental suffering.

Another proposed indicator of suffering has been whether the behaviour patterns of hens in battery cages differ from those of feral fowl, or Burmese red jungle fowl (Gallus gallus spadiceus), which is thought to be the wild form (WoodGush 1971). Thorpe $(1965,1967)$ argues that where animals are kept in situations that suppress their natural behaviour patterns, then suffering may well result. Hens in battery cages are physically prevented from performing many behaviours such as roosting, dust-bathing and ground-scratching. The birds cannot flap their wings, walk more than a few steps and are frustrated in their nesting behaviour (Wood-Gush
\& Gilbert 1969; Wood-Gush 1972). Such a major disruption of the 'normal' behaviour patterns should immediately alert us to the possibility of suffering but does not in itself constitute evidence that the animals are suffering (Ewbank 1968). Battery-kept hens might, for example, show less anti-predator behaviour than unrestricted fowl, but it would be implausible to argue from this that the birds were suffering from lack of anti-predator behaviour.

The Brambell Committee (Report, 1965) argued that the best indicator of suffering in other species was by analogy with the symptoms known to accompany mental suffering in human beings. To draw too close a parallel in this respect is, however, most dangerous. The 'fear grimace' of the chimpanzee, which to the human eye looks like a happy smile is in fact given in situations which the animal finds fearful (Jolly 1972). So even in an animal which is very closely related to us there is the possibility of serious error if the analogy with our own expressions is drawn too closely. How much greater is the possibility of error in animals which are even less like ourselves and have evolved their own independent ways of expressing emotion? At first sight it also seems humane to decry certain husbandry practices on the grounds that we ourselves would not like to be housed in this way. Whilst we must never forget the 'common ground' that may exist between us, and other animals, neither should we forget that different species may have genuinely different requirements. Baby jackdaws relish regurgitated worms, which I would not.

Physiological measures of 'stress' (Selye 1952) such as increased activity of the pituitary and adrenal cortex and development of gastic ulcers have also been used to indicate which conditions animals find stressful. Duncan (1974), in a discussion of this in relation to animal welfare, points out that there are difficulties in measuring physiological changes in living animals. There is also still the problem of relating changed physiological state to the animal's subjective feelings of distress. Animals may suffer before any physiological disturbances are detected or there may be physiological changes totally uncorrelated with suffering.

There is, however, another, possibly more direct way of inferring what an animal's feelings are, at least its feelings about a particular environment. This is to allow the animal to express those feelings by being given the opportunity to move out of that environment if it wants 
to. For example, if we want to know whether hens dislike battery cages, the hens could be given the opportunity to choose between battery cages and some other environment and allowed to 'vote with their feet'. If it were to turn out that hens have a very strong preference for environments other than battery cages and if they would repeatedly perform some task for the 'reward' of being allowed out of a battery cage, then we could say that they disliked battery cages. If, on the other hand, they did not seem to show a very strong preference one way or the other, we might be less inclined to say that they disliked them. Hughes \& Black (1973) have shown that hens given the opportunity to stand on different sorts of cage floor spent more time on hexagonal mesh than on coarse rectangular mesh or than on perforated steel sheet. It seems very likely that the hens 'like' some floors more than others. The reason why environmental preference is very likely to be closely correlated with an animals subjective feelings is that natural selection will have favoured such a connection. We should expect co-evolution between an animal's fitness in different environments and the capacity of each environment to evoke escape or settling behaviour (Levins 1968). As Orians (1971) puts it: 'birds should evolve to be more "turned on" by habitats in which their fitness is greater'.

This paper describes a number of experiments on habitat preference in domestic hens. The experiments could be taken from a strictly behaviourist viewpoint with no connotations of subjective feelings. However, if the preceding arguments are accepted, they may also be seen as a first step towards developing experimental methods to deal with the mental experiences of animals.

The first experiment is an attempt to find out where battery-kept hens choose to spend their time when given the opportunity to be either in a battery cage or in a much bigger pen. The birds were given continuous access to these two environments over a period of $12 \mathrm{~h}$. Where would they go? Would they ever re-enter a battery cage once they had left it? Would their choice be influenced by the time of day or by the lack of familiarity with the pen?

\section{Experiment 1: Where do Battery Kept Hens Go if Given Continuous Access to Battery Cages and a Larger Pen?}

\section{Methods}

Twelve Sykes Tinted hens which had been reared commercially on deep litter by Ross
Poultry Ltd, were used for this experiment. At the age of 18 weeks they were put into Patchett battery cages (floor space $0.38 \times 0.43 \mathrm{~m}$ ) with two birds per cage.

The birds were housed in a light-proof shed, on a 'step-up' system of lighting and fed commercial mash. At the age of 32 weeks they were tested individually by being placed in the centre of a pen (dimensions shown in Fig. 1). The floor of the pen was covered with wood shavings. Two Patchett battery cages with the backs removed to permit access were placed at one end of the pen. The floor of the backs of the battery cages was flush with the floor of the pen, so that a hen could walk easily in and out of the battery cages. The position of the two battery cages was changed from one side of the pen to the other for different hens. Food and water were available in equal amounts in similar troughs in the pen and the battery cages. Each bird was tested for $12 \mathrm{~h}$ but observations were made only once in each hour for $5 \mathrm{~min}$ at regular intervals. At the beginning of a test, an individul bird was placed in the centre of the large pen. It was left to adjust for $5 \mathrm{~min}$ and then the first observation session was begun. For subsequent observations, I entered the hut $5 \mathrm{~min}$ before an observation was due, to allow the bird to adjust to my presence, and then for $5 \mathrm{~min}$ recorded whether the bird was in the pen or one of the battery cages. I also recorded where and when any eggs were laid. In order to separate the effects of time of day from those of familiarity with the test apparatus, the tests of different birds were started at different times of day. One bird would be tested from 08.30 until 20.30 hours, another (on its testing day) from 10.30 to 20.30 hours and then again from 08.30 until 10.30 hours the following morning and so on. This means that many of the birds were removed from the apparatus overnight and restarted in the morning. The birds were at the time of testing

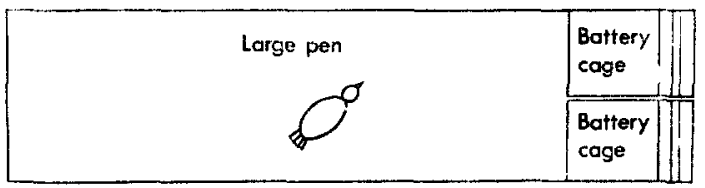

Fig. 1. Diagram of the large pen and battery cages used in experiment 1 . The battery cages had the backs removed so that the hens could wander freely in and out. The floor of the pen was $2.6 \times 0.82 \mathrm{~m}$ and was covered with wood shavings. The floor space of each battery cage was $0.38 \times 0.43 \mathrm{~m}$, the floor being of plastic covered rectangular mesh. 
on a 14-h light/dark, schedule with the lights coming on from 07.45 hours daily.

\section{Results}

In order to ensure that the results represent independent observations, the preference of the birds between pen and battery cage were first calculated as where the birds were standing at the beginning of each 5-min observation session (i.e. 12 observations for each of 12 birds). On this measure, 5 out of the 12 birds preferred the battery cages in the sense that the majority of their observation sessions found them standing in one of the battery cages, and 7 preferred the pen. Overall, there was no significant preference one way or the other, using a Wilcoxon Matched Pairs Test on the sign and magnitude of the differences $(N=12, P>0.05$ two-tailed (Siegel 1956)). This is somewhat surprising in view of the fact that the combined floor area of the two battery cages was so much smaller than the floor area of the pen (See Fig. 1) so that by chance one might have expected them to be seen more often in the pen. Through the $12 \mathrm{~h}$ of the test ( 08.30 to 20.30 hours), just under half the birds were seen in one of the battery cages (Fig. 2). The data from Fig. 2 can be rearranged so that the position of the hens is seen at different times since the beginning of their own individual tests rather than the time of day (made possible by the design of the experiment in which birds started their tests at different times of their day). Figure 3 shows such a rearrangement and the birds seemed not to change in how likely they were to be in pen or battery cage throughout their tests, even though they might be expected to have become more familiar with the pen the longer they had been in the apparatus.

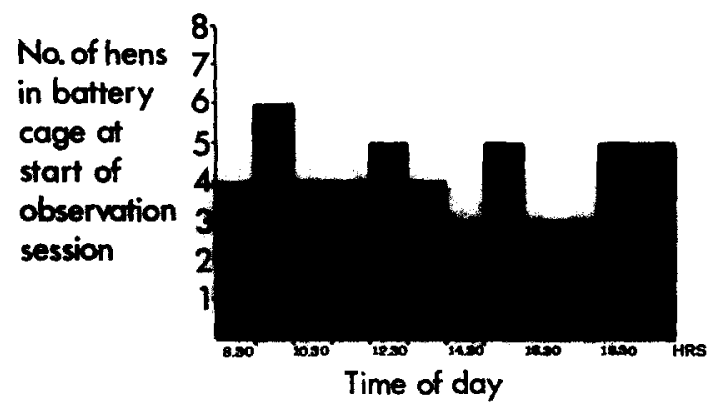

Fig. 2. Numbers of hens (out of a total of 12) in one of the battery cages at the beginning of each 5-min observation session throughout a 12-h day.
Another measure of preference which makes use of rather more of the data is how many complete minutes of a 5-min observation session a hen spent in pen or battery cage. The maximum possible in any one environment would be 5 , but if a hen repeatedly moved between the two, she could score 0 complete minutes for either environment. In any one 5-min observation session, a hen could be said to prefer one environment over the other depending on how many complete minutes she spent in each. Out of her 12 observation sessions she could be said to prefer one environment over the other if the majority of sessions showed a preference for this environment. Using this measure, four hens preferred the battery cages, seven preferred the run and one scored equally for the two environments, but the difference is not significant $(P>0.05$ Wilcoxon Test, two-tailed). Nor was there any tendency for the hens to spend more complete minutes in either environment depending on the time of day (Fig. 4) or how long they had been in the apparatus (Fig. 5). Nine of the hens laid an egg during the course of being tested, six in the pen and three in one of the battery cages but the figures are too small to draw any conclusions.

\section{Discussion}

The really rather surprising result of this experiment was the lack of demonstrated preference for either the pen or the battery cages. Of course, such a negative result does not imply that the hens do not have a preference: it could simply be that the preference was not demonstrated in these particular experimental conditions.

One reason why a preference was not demonstrated may have been that the chickens did not regard the pen as sufficiently different from the

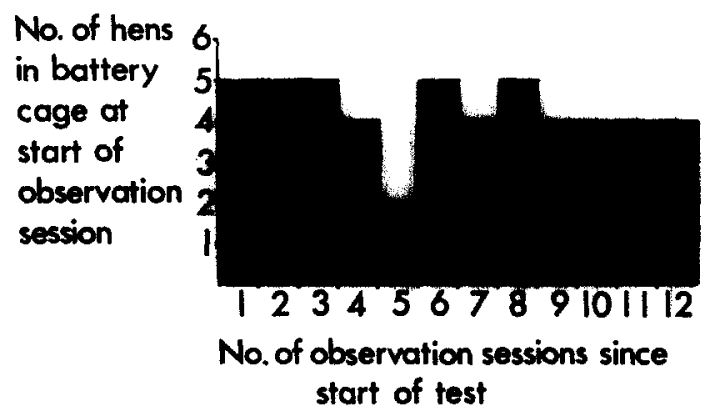

Fig. 3. Numbers of hens (out of a total of 12) in one of the battery cages at the beginning of each 5-min observation period throughout a 12-h test. 
battery cages to exhibit a preference between them (both pen and battery cage were inside, and the main differences were that the pen was. larger and had the floor covered with wood shavings). To meet this possibility, all the experiments described below involve testing a hen's responses to two environments which differed in very many more ways. The two environments were a battery cage and a hen-run outside in the garden.

The second reason for the apparent lack of preference may have been the particular method of testing. It is known that a hen's preference may be strongly affected by how the preference is measured. Hughes (1976) tested the preference of domestic hens for wire or litter floors and found that the birds chose differently depending on whether they were given constant access to both floor types or whether they had to make a choice between separate cages, where the choice was irrevocable for several hours. Because of the possibility that the method of testing described above may have given a misleading impression of the kinds of environments that chickens like and dislike, I have adopted two other methods of assessing the relative attractiveness of environments to hens.

The first of these methods involved releasing a hen from a starting box and measuring how quickly she moved into either a battery cage or a hen-run. These experiments are described in detail elsewhere (Dawkins 1976). The results showed that using this particular measure of

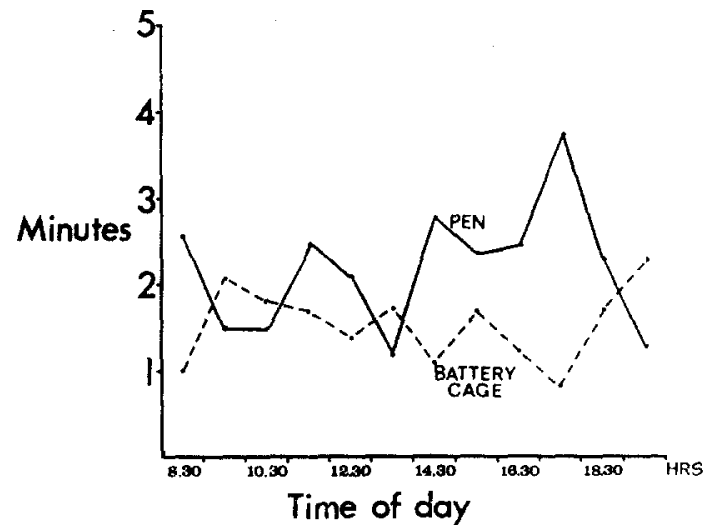

Fig. 4. Mean number of complete minutes spent by 12 hens in a battery cage (- - - ) and pen (- - in each of 125 -min observation sessions throughout the day. There is no significant tendency for the time spent in either environment to be different at different times of the day (Friedman two-way analysis of variance, $P>0.5$ ). preference, battery-kept hens initially preferred battery cages to a run in the garden in the sense that they moved more quickly into a battery cage than into an outside run. However, this preference was found to be highly dependent on the environment in which the hens had been living before being tested. Hens which had been living outside in a garden hen-run preferred the run, while caged birds preferred the battery cage. So the initial reluctance of a battery-kept hen to enter a run was probably due to its strangeness rather than to its undesirability. It seemed very important, therefore, to investigate precisely how much of the hen's behaviour was due to the unfamiliarity of the environments and to plot the time course of adjustment to the new environment. This was done in the experiment to be described next by repeatedly offering a hen a simultaneous choice between a run and a battery cage. When she had made her first choice, she was then confined for $5 \mathrm{~min}$ in whichever environment she had chosen and then replaced in the starting box and offered the same choice again. As the trials progressed, therefore, the hen would gradually accumulate experience of being confined in each of the two environments and by making her choose repeatedly, any changes in her preference could be monitored as a function of this experience.

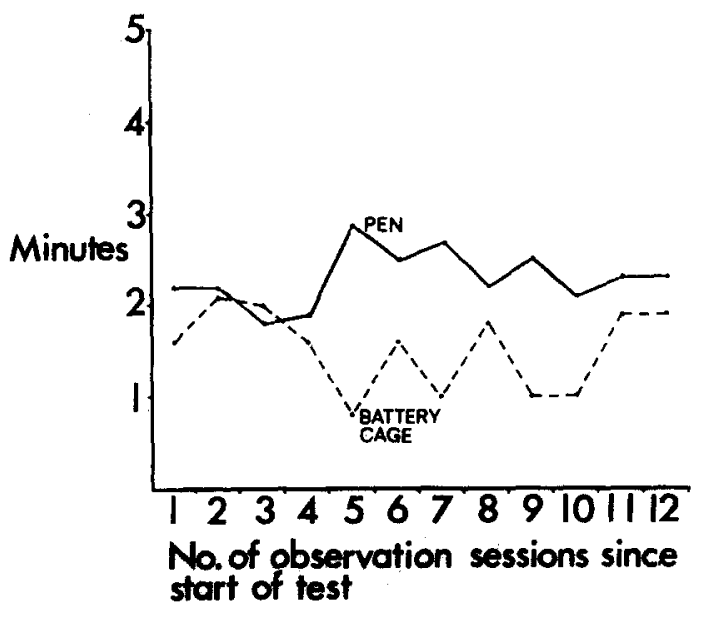

Fig. 5. Mean number of complete minutes spent by 12 hens in a battery cage (-..-) and pen $(-)$ in each of 12 5-min observation sessions throughout the 12-h test. There is no significant tendency for the time spent in either environment to vary depending on how long the birds have been in the apparatus (Friedman two-way analysis of variance, $P>0.90$ ). 
Since the conditions in which the hens had been living before being tested is known to have a profound effect on their performance in a test, (Dawkins 1976), two groups of hens were used, one accustomed to living in battery cages and one group used to living outside in the garden.

\section{Experiment 2: Do Hens Choose a Battery Cage or an Outside Run and Does the Cholce Change with Experience?}

\section{Methods}

Fourteen Sykes Tinted hens, aged 48 weeks at the time of testing, were used for this experiment. They had been reared commercially on deep litter by Ross Poultry Ltd, until the age of 20 weeks. On arrival in Oxford they were randomly divided into two groups: half were put outside into a hen-house and run (house $1.83 \times$ $1.14 \mathrm{~m}$; run area $7.34 \mathrm{~m}^{2}$ ); half were kept indoors in Patchett battery cages (floor space $0.38 \times 0.43 \mathrm{~m}$ ) with two birds in each cage.

The birds were individually given a choice between the two environments presented as the alternatives in a T-maze (see Fig. 6): an outside hen-run $(1.53 \times 0.76 \times 0.9 \mathrm{~m}$ high) made of wood and chicken wire and supplied by Park Lines Ltd, and a Patchett battery cage with the back removed to allow a hen to enter. For technical reasons it is very difficult to present a choice between a battery hen-house and a garden run, so a compromise in the form of a small hut on wheels that could be moved to any desired position, was adopted. The hut was lit and heated as much as possible like the house in which the hens had been living, and in order to simulate a 'battery' of cages, the hut contained three battery cages, the middle one of which was the test cage.

Each hen was offered this choice 24 times successively, between the hours of 07.30 to 11.00 and 16.30 to 18.30 daily, extending over several

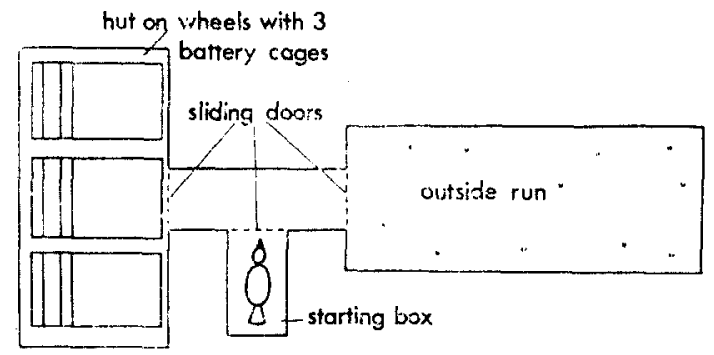

Fig. 6. Diagram of the choice test apparatus. The run measured $1.83 \times 0.76 \times 0.9 \mathrm{~m}$ high. The floor space of each battery cage was $0.38 \times 0.43 \mathrm{~m}$. days. Only when one hen had completed her 24 choices was the next hen started. For each choice, an individual hen was placed in the starting box with the door closed for $1 \mathrm{~min}$. The door was then raised and the hen released into a corridor from which she could see simultaneously the run and the battery cage. The time from the raising of the starting box door to when the hen entered one of the two test environments was measured and called the latency of choice. A hen was considered to have made a choice only when she had put both feet in one or other environment. If a hen failed to move out of the starting box within $15 \mathrm{~min}$, she was placed gently in the centre of the corridor (this happened in about $10 \%$ of trials). In order to ensure that the hen had a standard and measured amount of time in the environment of her choice, once she had entered it, the door leading to it was closed behind her and she was shut in for $5 \mathrm{~min}$. After this time, she was returned to the starting box and the next trial begun. In this way, a hen gradually accumulated 5-min blocks of experience of the environments she chose. A hen which had been living inside a battery cage was given its 24 trials following the series of a hen that had been living in the garden so that test order could not be a confounding variable in the comparison between the two groups. The position of the two environments with respect to the choice corridor was changed daily to avoid position effects. Food was available in similar troughs in both environments.

\section{Results}

As expected from previous work with latencies to the two environments presented successively (Dawkins 1976), the first choice of the hens was related to the environment in which they had been living. All seven of the hens which had been living in the garden chose the run on their first trial whereas only three of the battery-kept birds did so $(P=0.05$, Fisher Exact Probability Test). However, the battery-kept hens very quickly began to change their pattern of choice and became more and more likely to choose the run as their trials proceeded (Fig. 7). This result is interesting as it would seem to suggest that only a relatively small amount of experience of the run (a matter of minutes) is sufficient to make even battery-kept hens prefer the run.

In addition to which environment was chosen, the latency of that choice also provides valuable information about the hens' preferences. These 


\section{a. BATTERY CAGED HENS}

No. of birds (out of 7) choosing run

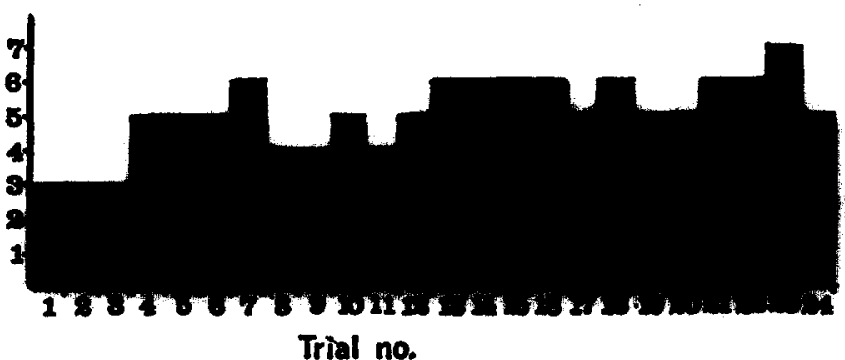

b. OUTSIDE HENS

No. of binds

(out of 7) choosing run

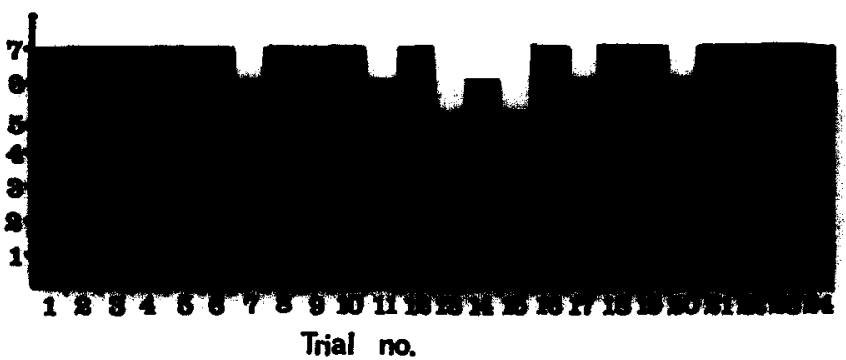

Fig. 7. Numbers of (a) battery-caged birds and (b) birds which had been living outside choosing the run in each of 24 trials. The difference between the two groups is significant only for the first three trials $(P=0.05$, Fisher Exact Probability test). The battery caged birds become more likely to choose the run as the trials proceed (Spearman rank correlation: $\mathrm{rs}_{\mathrm{s}}=0.35$; $N=24, P<0.05$ ).

latencies were, however, so variable both between individual birds and from trial to trial even of the same bird to the same environment that graphs for the 14 birds are presented separately in Fig. 8. Each graph incorporates two kinds of information: information about which environment the bird chose and information about the latency of choice, plotted cumulatively as the trials progressed. The bird could allocate its testing time between three separate places: the run ( $5 \mathrm{~min}$ at a time), the battery cage (also a maximum of $5 \mathrm{~min} /$ trial), and the choice corridor (this time being measured as the latency of response). After each trial, a certain amount of time would have elapsed since the beginning of the series for that bird and that time could have been spent in some or all of those three environments. Each graph plots cumulatively the proportion of the total test time spent in run and battery cage after different numbers of trials. The direction and slope of the graph shows the effect of previous experience, for example, a positively accelerating line would mean that the more time a bird spent in an environment, the more time she would spend in the future in that same place. Fig. 8(a) shows that for six of the hens kept in battery cages the proportion of time spent in the run gradually increased over 24 trials. Only one hen consistently spent more time in the battery cage and even this hen began to spend more time in the run towards the end of the series. On the other hand, the amount of time spent in the battery cage remained roughly constant or dropped off. This implies that whereas the effect of being in the run was to increase the future amount of time the bird spent in run, this was not true of the battery cage. This would seem to be a fairly objective way of saying that hens 'liked' the experience of being outside in the run more than they 'liked' being in a battery cage. Future experiments might profitably involve recording details of the behaviour of the hens during the 5-min period after each choice. 
Hens which had been living outside (Fig. 8(b)) tended to show consistently high levels of time in the run and certainly no tendency to increase time spent in the battery cage as a result of entering the battery cage. Most of them entered once or twice at the most and never again.

\section{Discussion}

These results show that battery-kept hens prefer an outside run to a battery cage, once initial unfamiliarity with the run has been overcome. These hens take a very short time to get used to the run (a matter of minutes) and to come to prefer it to their familiar cages. The more experience of the run they have, the more likely they are to choose to spend time in the run in the future. Being in a battery cage, on the other hand, does not seem to increase the likelihood that the hens will choose to spend time in a battery cage in the future, either for batterykept birds or for hens which have been living outside in a garden run. Birds which have been living outside consistently prefer the run over over the battery cage to a very marked extent.

Although these results give a preliminary indication that hens 'like' (as revealed by their behaviour) an outside run more than they 'like' a battery cage, there is a long way to go before any conclusions can be drawn about the extent to which hens suffer in battery cages. If a man were to be given a choice between a $£ 1$ note and a $£ 10$ note, for example, and he consistently

\section{Cumulative}
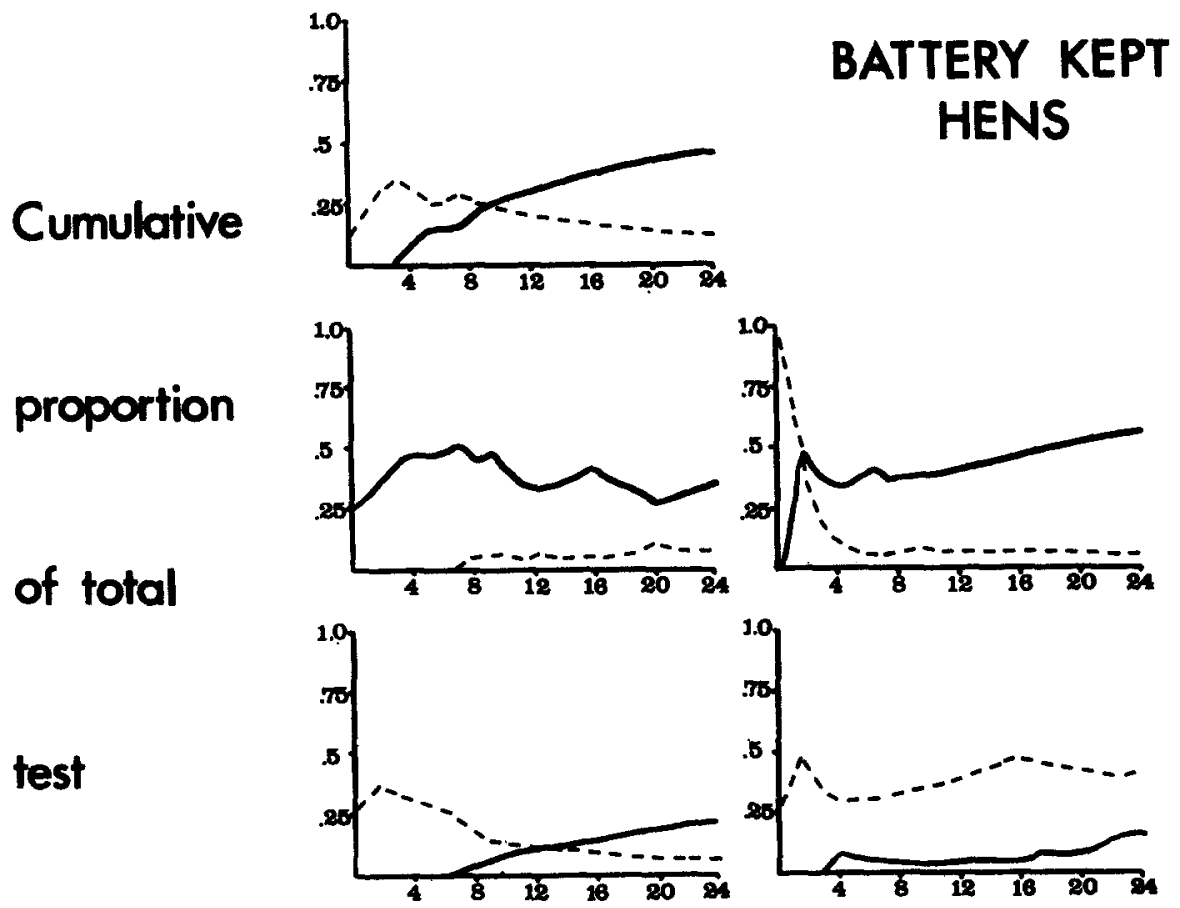

time
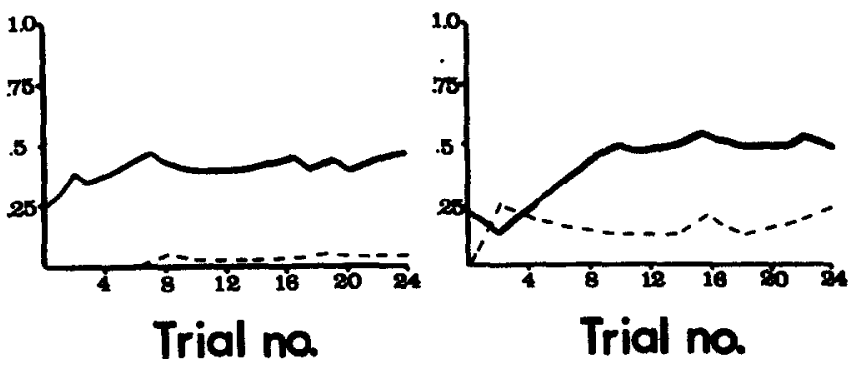

Fig. 8 (a) 


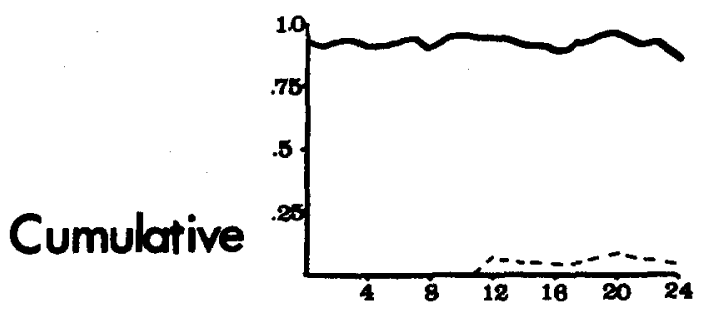

\section{OUTSIDE HENS}
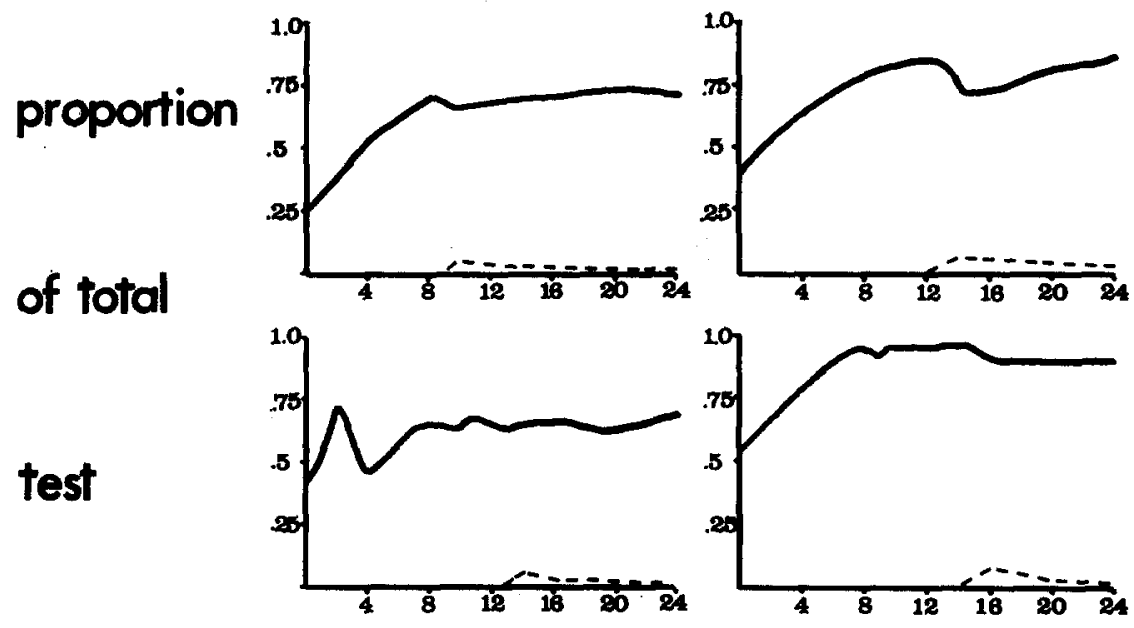

time
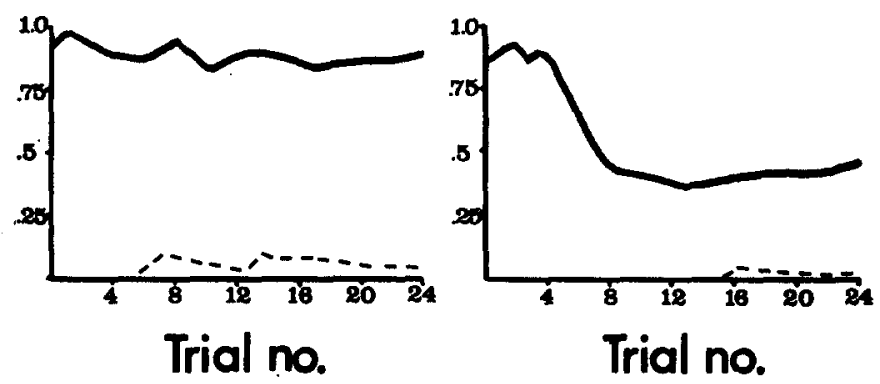

Fig. 8 (b)

Fig. 8. (a) cumulative proportion of total test time which seven individual battery-kept hens spent in the run $(-)$ and the battery cage (-- - $)$ during the course of their 24 trials (for details see text). (b) Cumulative proportion of total test time which seven individual hens which had been living outside in a garden run spent in the run (-) and the battery cage $(----)$ during the course of their 24 trials.

chose the $£ 10$ note, we could hardly be entitled to conclude that he suffered in the presence of single pound notes. Preference per se cannot be used to infer suffering or distress. It can only be used in this way if we can establish how great the preference is in terms of some yardstick, such as how much of some other commodity an animal is prepared to give up in order to obtain something. For example, hens are known to be very social animals and the sight of other hens appears to increase the attractiveness of an environment, since hens moved more quickly into a place where there were other hens (Dawkins 1976). Would hens still choose an outside run if it meant isolation from their flock mates? If they did still prefer an outside run under these circumstances, we could conclude that they 'liked' being in the run more than being with other hens. If the opposite result were found, and they chose to be with the other birds, 
then the conclusion might be that although they prefer a run, other things being equal, this preference is not as strong as their attraction to other birds. In this way it should be possible to get the hens to rank their preferences for different commodities. In the next experiment reported below, hens were offered such a choice between an outside run in which they would be alone, and a battery cage near other birds.

\section{Experiment 3: Do Hens Prefer an Ontside Run on Their Own or a Battery Cage Near Other Hens?}

\section{Methods}

Ten Sykes Tinted hens which had been used for the previous experiment were used for this test. Haif the birds were from each group, and since being tested previously, had been returned to their original living conditions, i.e. the battery-kept birds had been living in cages and the outside group in the garden. This experiment took place immediately after the previous one, but since this had taken 5 weeks to complete, the time lag between the two was different for different individuals. The choice apparatus was the same as that used in experiment 2 except that the two battery cages on either side of the test cage in the hut (see Fig. 6) were not empty as in the previous experiment, but each contained a single bird unfamiliar to the test bird. This meant that the choice presented to test the bird was a battery cage with other birds in cages on either side of it and an outside run in the garden without other hens. In order to make sure that the birds realized that there were other birds in the battery hut but not in the run, the experimental procedure was rather different from the earlier experiment. Before the actual choice was presented, each bird had a series of 'training' trials. in which entry to one environment was prevented by closing the sliding door leading to it and the bird had, therefore, to stay in the choice corridor or go into the other environment. All the birds eventually went into the single available environment upon which they were shut in for $5 \mathrm{~min}$. Three of these training trials were given to each environment so that by the end of the six trials, the bird had had at least $15 \mathrm{~min}$ experience of both environments. The seventh test was the choice test, with the bird having access to both environments simultaneously. Only one such choice test was given to each bird. One bird received its six training trials and it choice test in quick succession, the entire test usually taking about $1 \mathrm{~h}$.
The latency of responses both during the training trials and the choice test was recorded. The position of the two environments was changed between individuals and each hen received the three training trials for each environment in alternation. Battery-kept and outside hens were tested equally often before and after each other. Another difference from the previous experiment was that there was no food available in either the run or the battery cage (the reason for this will become apparent from the next experiment).

\section{Results}

In the final choice test, 9 out of the 10 birds chose the run by themselves over the battery cage near other birds. The one bird that chose the battery cage was a bird that had been living outside and was showing pre-egg-laying activity. She laid an egg soon after her test so her choice behaviour may have been temporarily upset. The latency data from the training trials also provides information about the hens' preferences for the two environments. If the latency of response to the battery cage in each of the 'battery alone' training trials is compared with the latencies in the 'run alone' training trials (Fig. 9) it will be seen that the birds took very much longer to enter the battery cage than the

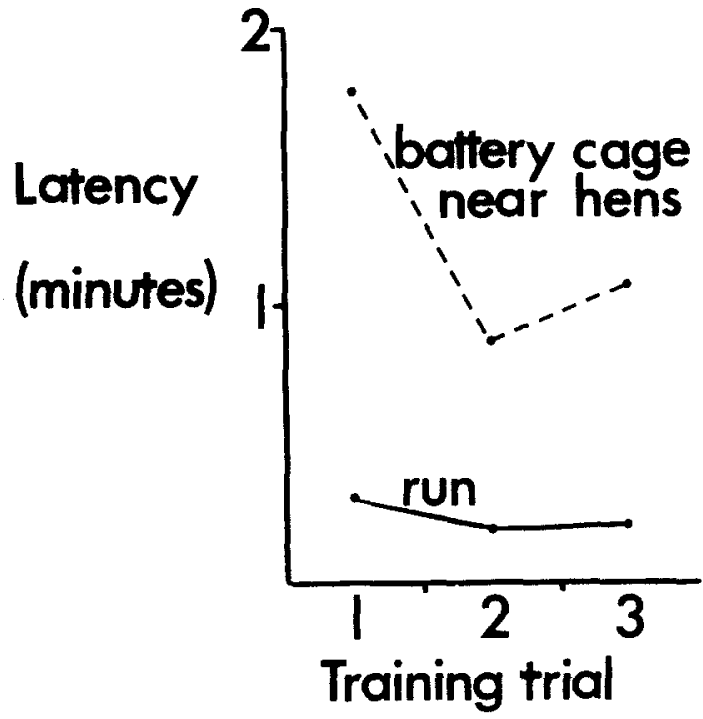

Fig. 9. Median response latency to battery cage presented alone and run presented alone in the training trials before a choice test. There is no significant tendency for these latencies to change over the three trials $(P>0 \cdot 1$, Friedman test, $N=10$ ). 
run. There was no significant trend for these latencies to change during the training period.

\section{Discussion}

Both by the criterion of hens choosing in a simultaneous choice test and by that of the latency of response when the environments were presented singly during 'training', it would seem that these hens preferred to be in an outside run, even though it meant being by themselves to being in a battery cage near other hens. This was true even though the previous experience of the test birds was rather varied. Half had been living in battery cages, and half outside and all had experienced various degrees of time in both environments during a previous test. It could be objected to this experiment that the period of 'training' was not long enough and that if there had been more training trials, the birds would have had more chance to 'take stock' of the two environments and might then have chosen differently. This may indeed be the case, but to judge by the previous experiment, even very short periods of time seem to be enough for a hen to learn about two environments. It would certainly be important to repeat this experiment with a longer period of training before we can draw any definite conclusions about how hens rank the opportunity to go into an outside run compared with the opportunity to be in a cage near other hens.

Another objection is that the fact that other birds are attractive to hens was inferred from previous work rather than demonstrated in the present experiment, so that, strictly speaking, all that can be concluded from this experiment is that hens prefer a run to a battery cage and this preference still exists even if there are other hens near the battery cage and not in the run. Nevertheless, taking this as a preliminary result, it would certainly seem to suggest that, subject to the objections just mentioned, the preference for the run over the battery cage would seem to be sufficiently strong to override the probable attraction of other hens. Further experiments along these lines are planned.

Another way in which it may be possible to assess the strength of hens' preferences for the run is by finding out whether they still choose the run if they can obtain food only in the battery cage. Will the attraction of the run outweigh that of food?
Experiment 4: Do Hens Prefer an Outside Run With No Food or a Battery Cage with Food? Methods

The ten hens which were used for experiment 3 were also used for this experiment. The choicetesting apparatus and procedure were the same as that described for experiment 3 , except that the battery hut did not contain the two hens in battery cages. The test battery cage this time had a trough of food and the outside run contained no food. The hens were not deprived of food before being tested, but the daily renewal of their food in their living cages was not carried out until after they had been tested. The hens were given six training trials, three to the battery cage alone and three to the run alone. As before, the seventh trial was the choice test.

\section{Results}

In the final choice test 3 out of the 10 hens chose the battery cage with food, 7 chose the run without food. This result is not significantly different from chance $(P>0 \cdot 1$ Binomial Test), but the fact that three hens (two battery-kept and one outside hen) chose the battery cage with food rather than the run means that at the very least, the hens' preferences are not absolutely clear cut, even though they were not deprived of food. Furthermore, the latencies of the response to the two environments presented singly (during the training trials) showed that the run was entered more quickly (Fig. 10). There seemed to be some tendency for the latency of response to the battery cage to go down over the three trials, perhaps as the birds learned that there was food in the cage, but this is not significant. However, it would certainly suggest that it would be worth repeating this experiment with a longer period of training and to more accurately 'titrate' access to a run against access to food.

\section{Discussion}

It was argued in the introduction that although it is very difficult, it may not be totally impossible to develop a methodology for dealing with the subjective feelings of animals. The long-term hope is to be able to assess animal suffering in a reasonably objective way. Different methods can all contribute something to our picture, but a particularly important source of evidence may be the kinds of environmental conditions that the animals themselves choose when given the opportunity to do so. The experiments described here, together with others such as those of Hughes (1976) are a first step in developing 


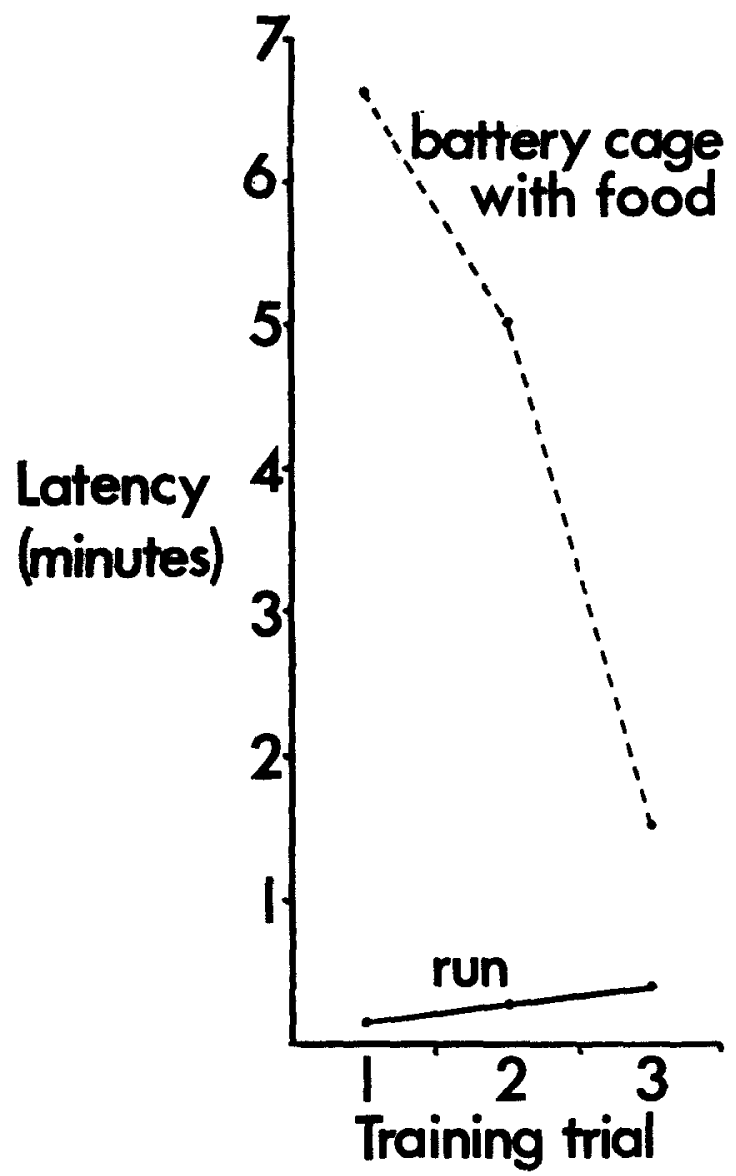

Fig. 10. Median response latency to battery cage presented alone and run presented alone in the training trials before a choice test. There is no significant tendency for these latencies to change over the three trials $(P>0 \cdot 1$, Friedman test, $N=10$ ).

such a methodology. The experiments do not, and could not, demonstrate the existence of mental events in hens. It would be possible to view these preference tests simply as overt behaviour, with no overtones of mental experiences. However, given that mental experiences will have evolved by natural selection, we would expect that behavioural choice and subjective feelings about the environments chosen would not be completely uncorrelated. If we had a clear idea of the kinds of situations that hens prefer and the extent to which they avoid less preferred environments, then we would be in a much better position to assess the mental states of hens in battery cages. It has been shown that hens prefer an outside run to a battery cage, once initial unfamiliarity with a strange environment has worn off. On the other hand, it is as yet impossible to say how strong this preference is. Hens given continuous access to a battery cage and a larger pen did not show evidence of preference one way or the other and the experiments in which access to a run is possible only if the hen chooses to forgo some other commodity such as food or other hens (experiments 3 and 4), do not enable firm conclusions to be drawn without further work along the same lines.

Before these laboratory experiments can be used to say anything one way or the other about the mental state of hens kept under commercial battery cage conditions, it is very important to establish the generality of these results. Is the preference the same whatever the method of testing used? Do different genetic strains of hens show different environmental preferences? Is the nature or extent of the preference affected by the type of battery cage used, for example a four bird cage, or by the stocking density? These questions can only be answered by further research.

I feel strongly that these are preliminary results and should not at the moment be used either to criticize or to support the battery-cage system for keeping laying hens. Anyone who uses these results for either of these purposes is in my view going beyond what our present knowledge warrants. However, I think it is important to continue to research into the question of whether hens suffer in battery cages along the lines that have been started, and I hope that one day such work will enable us to take an objective and humane judgment on life in a battery cage.

\section{Acknowledgments}

I am very grateful to the Royal Society for Prevention of Cruelty to Animals for financial assistance and to Dr R. Dawkins for reading the manuscript. I would also like to thank Miss J. Lomer for valuable technical assistance.

\section{R E F E R E N C ES}

Brambell, F. R. (Chairman) 1965. Report of the Technical Committee to Enquire into the Welfare of Antmals kept under Intensive Livestock Systems. Command Paper 2896, H.M.S.O., London.

Brophy, B. 1972. The ethical argument against the use of animals in biomedical research. In: The Rational Use of Living Systems in Biomedical Research. U.F.A.W., Potters Bar, Hertfordshire.

Dawkins, M. 1976. Towards an objective method of assessing welfare in domestic fowl. Appl. Anim. Ethol., 2, 245-254.

Duncan, I. J. H. 1974. A scientific assessment of welfare. Proc. Br. Soc. Anim. Prod., 3, 9-19. 
Ewbank, R. 1968. The behavior of animals in restraint. In: Abnormal Behavior in Animals (Ed. by M. W. Fox), pp. 159-178. Philadelphia: W. B. Saunders.

Griffin, D. R. 1976. The Question of Animal Awareness. New York: Rockefeller University Press.

Hughes, B. O. 1976. Preference decisions of domestic hens for wire or litter floors. Appl. Anim. Ethol., 2, 155-165.

Hughes, B. O. \& Black, A. J. 1973. The preference of domestic hens for different types of battery cage floor. Br. Poult. Sci., 14, 615-619.

Jolly, A. 1972. The Evolution of Primate Behavior. New York: Macmillan Co.

Levins, R. 1968. Evolution in Changing Environments. Princeton, N.J.: Princeton University Press.

Orians, G. 1971. Ecological aspects of behavior. In: Avian Biology. Vol. I (Ed. by D. S. Farner \& J. R. King), pp. 513-546. London and New York: Academic Press.

Ryder, R. 1971. Experiments on animals. In: Animals, Men and Morals (Ed. by S. \& R. Godlovitch \& J. Harris), pp. 41-82. London: Victor Gollancz Ltd.

Selye, H. 1952. The Story of the Adaptation Syndrome. Montreal: Acta, Inc.

Siegel, S. 1956. Nonparametric Statistics for the Behavioral Sciences. New York: McGraw-Hill.
Singer, P. 1976. Animal Liberation. London: Jonathan Cape.

Thorpe, W. H. 1965. The assessment of pain and distress in animals. Appendix III. Brambell Committee Report, Command Paper 2896, H.M.S.O., London pp. 71-79.

Thorpe, W. H. 1967. Discussion to Part II. In: Environmental Control in Poultry Production (Ed. by T. C. Carter). British Egg Marketing Board Symposium No. 4. Edinburgh: Oliver \& Boyd.

Wall, P. D. 1974. 'My foot hurts me': an analysis of a sentence. In: Essays on the Nervous System. A Festschrift for Professor J. Z. Young (Ed. by R. Bellairs \& E. G. Gray), pp. 391-406. Oxford: Clarendon Press.

Wood-Gush, D. G. M. 1971. The Behaviour of the Domestic Fowl. London: Heinemann.

Wood-Gush, D. G. M. 1972. Strain difference in response to sub-optimal stimuli in the fowl. Anim. Behav., 20, 72-76.

Wood-Gush, D. G. M. \& Gilbert, A. B. 1969. Observations on the laying behaviour of hens in battery cages. Br. Poult. Sci., 10, 29-36.

(Received 17 November 1976; revised 26 January 1977; MS. number: 1585) 